\title{
Determination in soils of PAH produced by combustion of biomass under different conditions
}

\author{
F. J. Gonzalez-Vila, J. L. Lopez, F. Martin, and J. C. del Rio \\ Instituto de Recursos Naturales y Agrobiología, C.S.I.C., Apartado 1052, E-41080 Sevilla, Spain
}

Summary. The nature and concentrations in soils of polynuclear aromatic hydrocarbons $(\mathrm{PAH})$ generated by combustion of pine biomass under different conditions was determined by gas chromatography-mass spectrometry after their enrichment by a simple clean-up procedure. The patterns of pyrogenic $\mathrm{PAH}$, presumably generated by thermal aromatization of biogenic precursors, vary for each sample. When burned at moderate temperature for a long period of time the most abundant homologues generated were alkylated derivatives of naphthalene, whereas phenanthrene alkyl derivatives were predominant after a forest wildfire, where higher temperatures are reached in less time. More condensed PAH included in well-known priority pollutant lists were detected only in minor amounts. No long persistence of $\mathrm{PAH}$ was observed in some soil samples analysed.

\section{Introduction}

Polynuclear aromatic hydrocarbons (PAH) are mainly introduced in nature by combustion of both vegetable biomass and fossil fuels. The PAH profiles produced in these processes depend not only on the original material burned but also on the combustion conditions, which can thus be responsible for obtaining similar PAH patterns from very different substrates $[1-4]$. It is thus necessary to investigate separately each potential source of PAH to know their environmental incidence.

In spite of the increased attention paid to the environmental consequences of forest fires, their potential as source of PAH has not been studied intensively. Whereas the presence of PAH mixtures in combustion emissions and smokes from vegetative and fossil fuel material has been amply demonstrated [5], there have been few works on the in situ accumulation of PAH generated by biomass combustion. During the last years forest fires have increased tremendously in number and size. In Andalucia (South Spain) alone, more than 40000 hectares of wooded and arboreal areas were destroyed in the last two years [6]. In this region also other processes of biomass combustion may lead to accumulation of PAH in agricultural soils. This has previously been demonstrated for the controlled burning of stubble fields [7], but not yet in the case of bonfires of olive or pine trees, when forest zones are converted into cultivable

Offprint requests to: F. J. Gonzalez-Vila lands, nor in the case of the production of charcoal from different vegetal species in home-made ovens.

In the present work we have taken advantage of the above mentioned different combustion processes to investigate the influence of different burning conditions upon the PAH patterns obtained from pine biomass. A rapid, sensitive and cost-effective procedure, already successfully applied to measure the concentration of $\mathrm{PAH}$ in composts and compost-amended soils [8], has been employed.

\section{Material and methods}

Soil samples were taken from the $0-10 \mathrm{~cm}$ superficial layer of various sites before (W-B) and after (W-A) a pine forest wildfire that took place in the Summer of 1986 and from the same site two years later (W-2); the site where an open bonfire of pine trees was made recently $(B)$ and 50 years ago (B-50); from soils which cover home-made ovens for the production of pine charcoal $(\mathrm{O})$; and from this charcoal itself $(\mathrm{P})$. In spite of the wide range of combustion temperatures involved in the various processes, the different soil samples can be considered representatives of possible $\mathrm{PAH}$ accumulation after pine biomass combustion varying the biomass quantity, time of burning and temperature.

The PAH enrichment protocol was described previously [8], and basically consists of an ultrasonic extraction with methyl chloride $(\mathrm{MeCl})$, redissolution of the crude extracts in isooctane and clean-up of the PAH-containing fraction by chromatography on alumina micro-columns (Sep-Pack cartridges). Sequential elution with $\mathrm{n}$-hexane and $\mathrm{MeCl}$ yield fractions enriched in n-alkanes and PAH respectively, which can be directly submitted to GC-MS analysis. About $90-95 \%$ of added internal standards were recovered in the final extracts. Table 1 shows the yield of the crude extracts and the different subfractions obtained from each sample.

A Hewlett Packard 5730 A gas chromatograph equipped with FID detector and a Hewlett Packard 5995 B GC-MScomputer system were used for separation, identification and quantitation of individual components. Separation of compounds was achieved using a $12-\mathrm{m}(0.32 \mathrm{~mm}$ i.d.) SE52 fused silica capillary column, with the oven temperature programmed from $50(1 \mathrm{~min})$ to $100^{\circ} \mathrm{C}$ at a rate of $30^{\circ} \mathrm{C}$ / min, and then from 100 to $280^{\circ} \mathrm{C}$ at $6^{\circ} \mathrm{C} / \mathrm{min}$, with $15 \mathrm{~min}$ final hold. Helium at a flow rate of $1.5 \mathrm{ml} / \mathrm{min}$ was used as carrier gas. The retention indices were very similar to those published elsewhere $[9,10]$. For identification of homologous series of alkyl derivatives, SIM fragmentograms at different ions were carried out. 
Table 1. Total organic carbon (TOC) and average yields of crude extracts and subfractions (dry weight basis)

brackets percentages of the total crude extracts

\begin{tabular}{lccccc}
\hline Sample & $\begin{array}{l}\text { TOC } \\
(\mathrm{mg} / \mathrm{g})\end{array}$ & $\begin{array}{l}\text { Tot. lipids } \\
(\mathrm{mg} / \mathrm{g})\end{array}$ & $\begin{array}{l}\text { Isooctane sol } \\
(\mu \mathrm{g} / \mathrm{g})\end{array}$ & $\begin{array}{l}\text { Fr. hexane } \\
(\mathrm{ng} / \mathrm{g})\end{array}$ & \multicolumn{1}{c}{$\begin{array}{l}\mathrm{Fr} . \mathrm{MeCl}^{\mathrm{a}} \\
(\mathrm{ng} / \mathrm{g})\end{array}$} \\
\hline W-B & 5.70 & 0.38 & 2.03 & 660 & $797(0.20)$ \\
W-A & 40.81 & 0.48 & 4.60 & 1865 & $2376(0.49)$ \\
W-2 & 21.53 & 0.43 & 3.70 & 1442 & $1801(0.41)$ \\
B & 88.50 & 0.23 & 10.20 & 7580 & $2730(1.18)$ \\
B-50 & 14.00 & 0.10 & 1.90 & 538 & $197(0.16)$ \\
O & 113.50 & 0.16 & 23.20 & 16120 & $6302(3.93)$ \\
P & 503.50 & 0.30 & 3.60 & 3610 & $1502(0.46)$ \\
\hline
\end{tabular}

Fig. 1. Total ion chromatograms of the PAH-enriched fractions from the soil samples before $(W-B)$ and after $(W-A)$ the pine forest wildfire. $\bigcirc$ Two cycles PAH'S; $\triangle$ three cycles PAH'S; 4/5 cycles PAH'S

\section{Results and discussion}

With the exception of some methylated fatty acids and a few long chain alkanes all interfering substances could be removed from the crude extracts, and the various samples gave well-resolved PAH patterns. Figures 1 and 2 show the total ion chromatograms (TIC) of some indicative PAHenriched fractions. A variety of two- to four-ring PAH covering a wide range of concentrations were detected in the samples along with other non-condensed aromatic compounds, mainly of biphenyl and hydroaromatic type. Only the first are identified on the chromatograms.

Table 2 shows the different types of compounds detected and their concentrations in each sample. The different isomer mixtures are not separated into single components, so the values show their total concentrations. Total amounts of biphenyl derivatives and hydroaromatic compounds reflecting the contribution of lignins and terpenoid compounds more or less altered in the different processes are also included.
From these results the following considerations and conclusions can be drawn:

a) In agreement with other authors $[11,12]$ the main types of PAH isolated after biomass combustion have naphthalene and phenantrene structure, while more condensed homologues with more than three cycles are present in minor amounts. The distributions are however not comparable with that reported for forest fire smoke aerosols [5]. As the degree of alkylation correlates closely with the temperature at which the compounds are formed $[1,2,13]$, the relative low concentrations of unsubstituted PAH together with the predominance of highly alkylated homologues suggest that mainly pyrolysis at low and intermediate temperatures took place.

b) Naphthalene derivatives, generated by thermal aromatization of phytosterols and sesquiterpenes $[12,14]$ present in high concentration in conifers [15], are nearly exclusively present in the sample $O$, the most abundant homologues being eudalene (C4-alkylnaphthalene) and cadalene (C5-alkylnaphthalene). The tendency of these compounds 


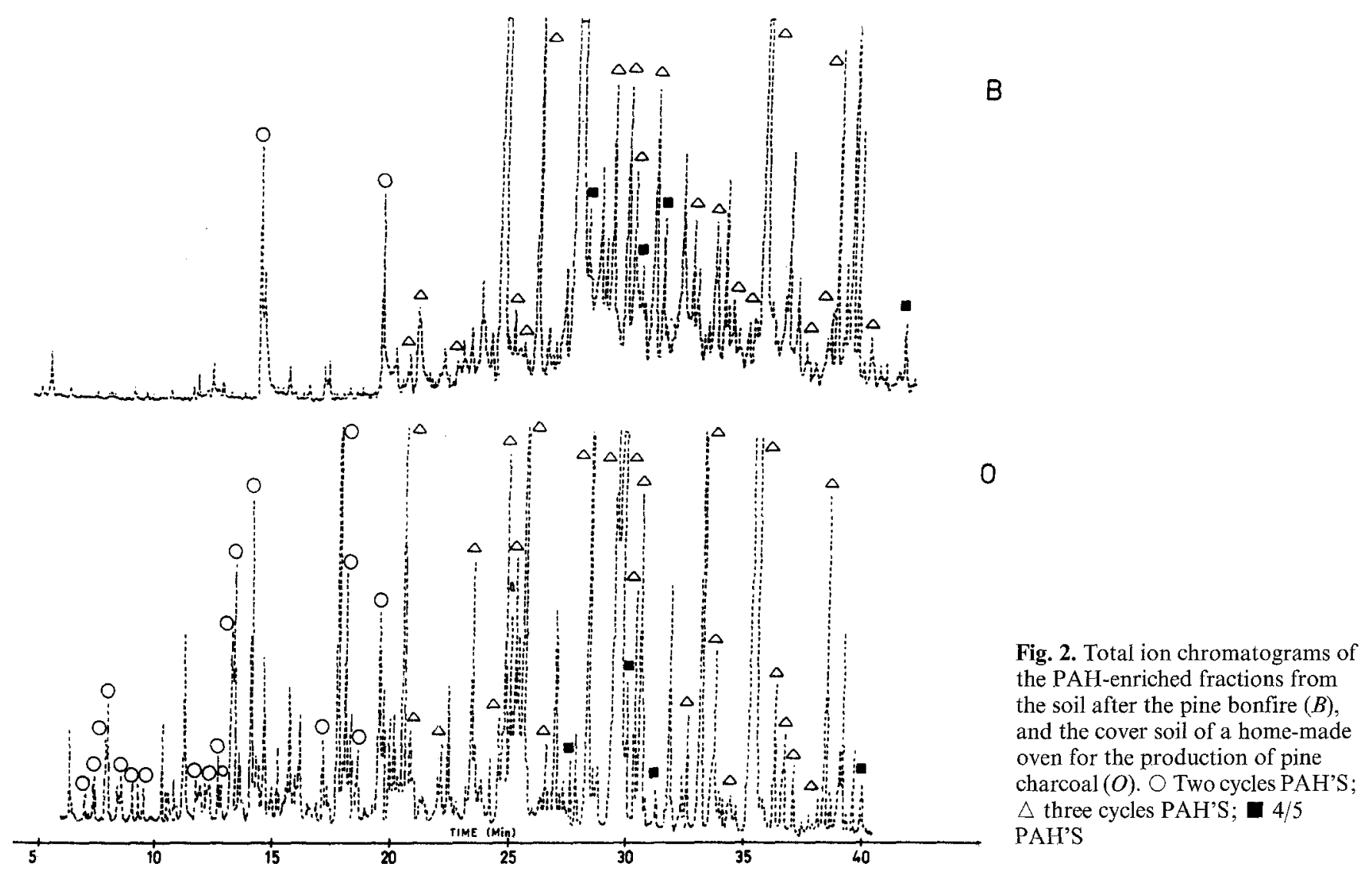

Table 2. Types and average concentrations ( $\mathrm{ng} / \mathrm{g}$ ) of compounds detected in the samples

\footnotetext{
a Pyrene, chrysene, benz(a)anthracene, benz(c)pyrene, perylene

b Dibenzofuran, xanthenes, alkylanthracene diones
}

\begin{tabular}{lrrrrrr}
\hline Compounds & W-A & W-2 & B & B-50 & O & P \\
\hline C2-alkylnaphthalenes & - & - & - & - & 195 & - \\
C3-alkylnaphthalenes & - & - & - & - & 170 & - \\
C4-alkylnaphthalenes & 12 & - & - & - & 285 & - \\
C5-alkylnaphthalenes & 38 & - & - & - & 513 & - \\
Fluorene and derivat. & 96 & - & 112 & - & 33 & - \\
Phenanthrene & 10 & - & 48 & - & 243 & 9 \\
C1-alkylphenanthrenes & 109 & - & 50 & - & 532 & 53 \\
C2-alkylphenanthrenes & 188 & - & 50 & - & 526 & 114 \\
C3-alkylphenanthrenes & 178 & - & 166 & 14 & 550 & 162 \\
C4-alkylphenanthrenes & 579 & 22 & 330 & - & 844 & 665 \\
C5-alkylphenanthrenes & 144 & - & 184 & 20 & 252 & 86 \\
4/5 cycles PAH's & 20 & - & 96 & - & 35 & 13 \\
oxygenated PAH's & 58 & 472 & 164 & - & 139 & 93 \\
Biphenyl derivatives & 92 & 1007 & 110 & - & 279 & 95 \\
Hydroaromatic comp. & 672 & 273 & 1226 & 144 & 1268 & 144 \\
\hline
\end{tabular}

c) Phenanthrene and an extended series of alkylated homologues arise from the thermal degradation of steroids and diterpenoid compounds [17], which are abundant in pine forest biomass [18]. The higher abundance of diterpenes in comparison which sesquiterpenes would explain the major abundance of phenantrene derivatives, even considering the loss of naphthalenic compounds in the smoke phase. Of the great variety of phenanthrene derivatives detected, retene (C4-phenanthrene), a typical product of the combustion of conifer vegetation [3], is the most abundant in all samples. This compound is the main product of the thermal 
aromatization of abietic acid, the most abundant resinic acid in conifers [19], and its degradative pathway has been well documented $[4,12,20]$. Considering also concentrations of dealkylation products such as C1-phenanthrene and phenanthrene, a correlation between the amounts of retene and quantity of biomass burned seems to be apparent.

d) Fluorene-type compounds were also detected after the pine forest fire (W), fluorene and fluorenone being the most abundant homologues. Fluorenone was also previously detected in industrial emissions from wood combustion [21]. Both are characteristic products of oxidation and decarboxylation of alkylphenanthrenes [22], under conditions of large concentrations of these compounds (observed in the control soil) and good ventilation.

e) PAH of more than three cycles were detected in the samples, pyrene and chrysene being the most abundant homologues. These compounds are generated by pyrolysis, condensation and cyclation of $n$-alkanes $[1,2]$ which are constituents of cuticular wax of conifers [23]. Non-detectable amounts of benz(a)pyrene, used in many investigations [24] as an indicator for the extent of contamination with carcinogenic $\mathrm{PAH}$, were found.

f) Oxygenated PAH, other than fluorenone, were detected in the samples. They have been detected associated with general airborne particulate matter, and may readily be formed by incomplete combustion of organic material and/ or photochemical degradation of $\mathrm{PAH}$ [21]. Anthracenediones and some alkylated homologues were most abundant in the control soil (W-B) and the soil W-2 than in the soil W-A, which indicates that they were rather formed in metabolic processes [25].

g) From the environmental point of view the total PAH accumulation implies the addition to soil of $2-4 \mathrm{~g} / \mathrm{ha}$ in extreme cases, an important input although much lower than those produced by fossil fuel combustion frequent in urban or industrial areas. In any case the concentration of potentially carcinogenic PAH accumulated in the soils was too low to give concern, in particular if the detoxification mechanisms that occur in soils, such as absorption, leaching, biodegradation, etc., are considered. These assumptions are confirmed by the low persistence of PAH in the soil samples analysed (W-2, B-50).

\section{References}

1. Blumer M, Youngblood WW (1975) Science 188:53

2. Youngblood WW, Blumer M (1975) Geochim Cosmochim Acta 39:1033

3. Ramdahl T (1983) Nature $306: 580$

4. Wakeham SG, Schaffner Ch, Giger W (1980) Geochim Cosmochim Acta 44:403

5. Simoneit BTR (1984) Atmos Environ 18:51

6. Infoca-89 (1990) Instituto Andaluz de Reforma Agraria. Ed. Junta de Andalucia

7. Lopez-Ruiz JL, Gonzalez-Vila FJ, del Rio JC, Martin F (1989) Advances in Mass Spectrometry, 11B, Longevialle P (ed). Heyden and Son Ltd., London, p 1796

8. Gonzalez-Vila FJ, Lopez-Ruiz JL, Martin F (1988) Biomed Environ Mass Spectr 16:423

9. Lee ML, Vassilaros DL, White CM, Novotny M (1979) Anal Chem 51:768

10. Beernaert H (1979) J Chromatogr 13:109

11. Severson RF, Snook ME, Arrendale RF, Chortyk OT (1976) Anal Chem 48:1866

12. Simoneit BRT, Mazurek MA (1982) Atmos Environ 19:2139

13. Ishiwatari R, Fukushima K (1979) Geochim Cosmochim Acta 43:1343

14. Schmeltz I, Tosk J, Hoffmann D (1976) Anal Chem 48:645

15. Guenther E, Gilbertson G, König RT (1975) Anal Chem 47:139

16. Atlas EL, Donnelly KC, Giam CS, Mcfarland AR (1985) Am Ind Hyg Assoc J 49:532

17. Wakeham SG, Schaffner Ch, Giger W (1980) Geochim Cosmochim Acta 44:415

18. Gleizes M, Marpau A, Pauly G, Bernard-Dagan C (1984) Phytochemistry 23:1257

19. Zinkel DF (1976) Phytochemistry 15:1073

20. Laflamme RE, Hites RA (1978) Geochim Cosmochim Acta $42: 289$

21. Yu M, Hites RA (1981) Anal Chem 53:951

22. Shulten HR, Simmleit N, Rump HH. (1986) Chem Phys Lipids $41: 209$

23. König J, Balfanz E, Funcke W, Romanowsky T (1983) Anal Chem 55:599

24. Aichberger K, Reifenauer D (1983) Processing and Use of Sewage Sludges, L'Hermitte P, Ott H (eds) Reidel, Dordrecht, p 161

25. Thomson RH (1965) Chemistry and Biochemistry of Plant Pigments, Chap. II, Goodwin TW (ed) Academic Press, London, p 309 